\title{
Trascendencia del pensamiento iusfilosófico de José Martí en la concepción de República para los pueblos de Nuestra América
}

\section{The Transcendency of José Martís Iusphilosophical Thought in the Conception of the Republic for the Peoples of Our America}

\section{Transcendência do pensamento iusfilosófico de José Martí na concepção de la República para os povos da Nossa América}

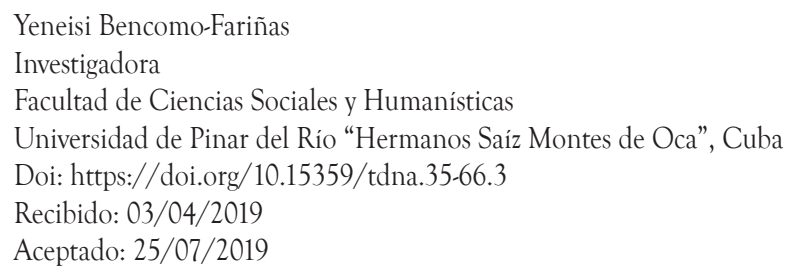

\section{Resumen}

José Martí ha sido catalogado como uno de los exponentes más altos de una tradición filosófica del siglo XIX, la cual que se continúa hasta nuestros días. Sus concepciones en el campo del derecho se sustentan sobre la base de la justicia, valor consustancial a la dignidad plena del hombre, centro de

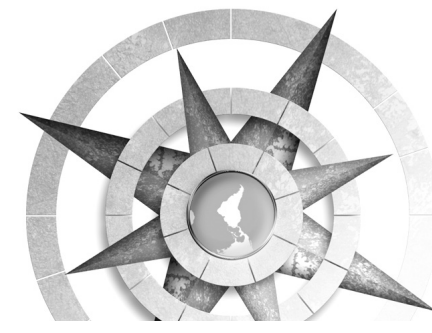

la axiología martiana y modulador del despliegue del resto de los valores jurídicos.

Esta alcanza su máxima expresión en la república que propuso para Cuba y para los demás pueblos de América Latina. El artículo presenta un análisis de las ideas iusfilosóficas de José Martí en torno al modelo de república que propone, válida en la actualidad, al sentar importantes bases para su contextualización en la realidad latinoamericana Este trabajo permite comprender el alcance del perfil iuspublicístico del Apóstol y, especialmente, su trascendencia para Nuestra América, donde la búsqueda de un modelo auténtico sigue siendo la constante para salvar la región ante los intentos de imposición de una cultura única en un mundo globalizado. 
Palabras claves: José Martí, pensamiento latinoamericano, axiología jurídica, república, América Latina.

José Martí has been called one of the highest exponents of a 19th century philosophical tradition, which continues to this day. His conceptions in the field of law are based on justice, an inherent value to the full dignity of men, center of Marti's axiology and modulator of the unfolding of the rest of the juridical values. The article presents an analysis of José Martís iusphilosophical ideas about the model of republic that he proposes, valid up to the present day, by laying important foundations for its contextualization in the Latin American reality. This work allows us to understand the scope of the Apostle's iuspublistic profile and, especially, its transcendence for Our America, where the search for an authentic model continues to be the key to save the region from the attempts to impose a unique culture in a globalized world.

Keywords: José Martí, Latin American thinking, legal axiology, republic, Latin America

\section{Resumo}

José Martí foi catalogado como um dos expoentes máximos de uma tradição filosófica do século XIX, que continua até aos nossos dias. Suas concepções no campo do direito são baseadas na justiça, um valor inerente à plena dignidade do homem, o centro da axiologia de Martí, e que modula a implantação de outros valores legais. Isto atinge sua máxima expressão na República que propôs para Cuba e os demais povos da América Latina. $\mathrm{O}$ artigo apresenta uma análise das idéias iusfilosóficas de José Martí sobre o modelo de república que ele propõe, válida nos dias de hoje, pois lança bases importantes para sua contextualização na realidade latino-americana. Esta pesquisa nos permite a compreensão do alcance do perfil iuspublístico do Apóstolo e, especialmente, de sua transcendência para Nossa América, onde a busca de um modelo autêntico continua sendo a constante para salvar a região das tentativas de impor uma cultura única em um mundo globalizado.

Palavras chave: José Martí, axiologia jurídica, república, América Latina

\section{Ideas preliminares}

La concepción martiana sobre lo jurídico es fundamentalmente deontológica, es un deber ser que se edifica desde los principios éticos del obrar humano, de ahí que quiso José Martí hacer de la ética el norte de la conducta de los hombres en sus relaciones jurídicas y sociales dentro de una comunidad reglada por el derecho. Si lo ético es predominante en Martí, su pensamiento jurídico hay que interpretarlo así para llegar entonces a la conclusión de la armonía
36 Trascendencia del pensamiento iusfilosófico de José Martí en la concepción de República para los pueblos de Nuestra América

Yeneisi Bencomo-Fariñas

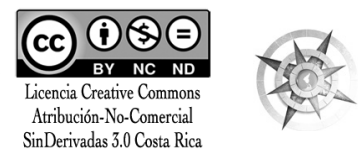

SinDerivadas 3.0 Costa Rica 
del derecho con la ética que es característica en el Maestro. En consecuencia, Martí no conceptuó el derecho como simples normas estáticas o intangibles, sino que le insufló un gran contenido moral, de manera que todo el derecho debía enmarcarse en lo ético.

Sin lugar a dudas, la concepción del derecho en América Latina ha de abandonar definitivamente aquella posición que limita su enfoque al puro normativismo kelseniano y que reconoce como derecho, únicamente, al conjunto de normas escritas; siendo necesario adoptar entonces otra postura, que, si bien respeta el contenido normativo del derecho, se sustenta en la protección y tutela dentro de la sociedad del contenido axiológico de este.

Nos adentramos así en el tema de la axiología jurídica, cuyo estudio permite ahondar en los valores que deben sustentar al derecho; encargándose del estudio de los valores que se encuentran incorporados al derecho positivo; investigando aquello que debe ser o debería ser en el derecho, frente a aquello que es; partiendo para ello de la realidad de que el derecho persigue siempre la realización de determinados valores jurídicos, insertándose el derecho, por tanto, en un orden más vasto: el ético-moral, fuera del cual carece incluso de sentido. En esta tarea actual que se concreta en la búsqueda de la fundamentación ética del derecho, resulta necesario ahondar en el pensamiento iusfilosófico de aquel que fuera catalogado como el hombre más universal de todos los tiempos: José Martí; y más aún, en la república moral que propuso fundar en todos los pueblos de América Latina, sobre la base del reconocimiento y de la defensa de un derecho popular acorde con las realidades estructurales y culturales de Nuestra América.

\section{La república martiana. Bases esenciales para su articulación en los pueblos de Nuestra América}

José Martí, tan cubano como latinoamericano, proclamó con voz certera que la república que se proponía construir era una "República con todos y para el bien de todos" (Martí, 1975, p. 279), cuya suprema aspiración era lograr que la ley primera fuera el culto de los cubanos a la dignidad plena del hombre, de ahí que, precisamente, fuera el hombre el centro en su proyecto encaminado a la construcción de la nueva república, estando entonces su lucha dirigida siempre a la consagración, como principio inviolable, del radical respeto al decoro del hombre, nervio del combate y cimiento de la república.

Empleó en múltiples ocasiones el término hombres nuevos americanos para referirse al hombre que debía surgir en la verdadera república, un hombre que pensara desde América y para América, por lo que, a su vez, debía ser tarea de 
Nuestra América formar a esos hombres. Previó así la necesidad de formar un nuevo tipo de hombre para enfrentar las nuevas condiciones de la región, la necesidad de crear la generación del futuro americano; el hombre que defendería a toda costa lo propio, lo autóctono de sus naciones.

Así, en su concepción republicana, rechazó Martí la imposición de modelos ajenos, valorando específicamente el problema nacional desde un punto de vista humanista universal enriquecido por su actividad revolucionaria; no limitando sus concepciones sobre la independencia a las relaciones políticas entre colonia y metrópolis; sino que fue más allá, diseñando un proyecto de la nueva república para Cuba y los demás pueblos de Nuestra América, cuyo centro no era otro que la realización plena de cada uno de sus ciudadanos.

Y es que Martí no se refirió en su constante lucha solo a la independencia de Cuba, sino que declaró, en más de una ocasión y de forma explícita, su comprometimiento con América Latina: "... cuando se tienen los ojos fijos en lo alto, ni zarzas ni guijarros distraen al viajador en su camino: los ideales enérgicos y las consagraciones fervientes no se merman en un ánimo sincero por las contrariedades de la vida. De la América soy hijo: y a ella me debo..." (Martí, 1975, p. 67).
Fue en el año 1875 cuando José Martí se radicó en México, poniéndose en contacto, por primera vez, con la población indígena, y fue tal su identificación con ella que, observando hacia el futuro, expuso que hasta que el indio no se incorporara a la lucha por la liberación de América, esta no alcanzaría su plena independencia, y defendiendo estas ideas escribió que: "Ni con galos ni con celtas tenemos que hacer en nuestra América, sino con criollos y con indios" (Martí, 1975, p. 69).

En este país, la política de Lerdo de Tejada reflejaba la inestabilidad de un Gobierno que se había propuesto la libertad como objetivo, compartiendo Martí los presupuestos teóricos del Gobierno, sin embargo, a raíz de la irrupción de Porfirio Díaz en Ciudad de México, decidió alejarse del país, cuando evidentemente la marcha hacia la libertad había sido truncada.

Esta tierra le permitió, asimismo, comprender de una manera más clara y directa la dinámica sociopolítica latinoamericana que emergía de la diversidad de modelos importados, y, confiando en su continente se lanzó a la construcción de la patria nueva: "El sueño comienza a cumplirse. América, gigante fiero, cubierto con harapos de todas las banderas que con los gérmenes de sus colores han intoxicado su sangre, va arrancándose sus vestiduras, va desligándose de 
estos residuos inamalgamables [...] va redimiéndose de su confusión [...] y ora vacilante, firme luego $[. .$.$] camina hacia$ sí misma” (Martí, 1975, p. 348).

Con estas ideas, iniciaba entonces su peregrinar por las tierras continentales hacia Guatemala, donde nuevamente abogó por la unidad al sentir los peligros de antiguas divisiones producto de las cuales había entrado la conquista. En esta nación adquirió Martí una visión del proyecto liderado por Justo Rufino Barrios, tomando mayor conciencia del desequilibrio en el cual vivían nuestras sociedades. La dirección política del país había pasado a manos de la pequeña burguesía agraria, grupo encabezado por Barrios, siendo obligdo por el afianzamiento liberal a reformar el derecho en un marco que ya no cedía lugar a las comunidades indígenas, sino a los propietarios.

Martí, aunque mantuvo cierto recelo hacia Barrios, postura que se justifica por su reciente experiencia en México, confió en los resultados de los Códigos guatemaltecos, sobre los que no tardó en dar su opinión, dejando plenamente esclarecido un concepto de identidad verdaderamente revolucionario para su tiempo:

Interrumpida por la conquista la obra natural y majestuosa de la civilización americana, se creó con el advenimiento de los europeos un pueblo extraño, no español, porque la savia nueva rechaza el cuerpo viejo; no indígena, porque se ha sufrido la injerencia de una civilización devastadora, dos palabras que, siendo un antagonismo, constituyen un proceso; se creó un pueblo mestizo en la forma, que con la reconquista de su libertad, desenvuelve y restaura su alma propia. (Martí, 1975, p. 100).

En sus consideraciones respecto a este cuerpo legal, dejó plasmados importantes criterios en el campo del derecho, al establecer que los nuevos Códigos guatemaltecos ni podían ser enteramente renovadores haciendo caso omiso de las relaciones sociales existentes, ni podían ser más avanzados y modernos de lo que el grado de desarrollo económico, político, social, cultural y espiritual del pueblo guatemalteco permitía; aludiendo además al hecho de que la elaboración de los nuevos Códigos, así como las formas institucionales que debían ser adoptadas, tenían que fundamentarse en el estudio de los afectos e intereses de los seres humanos que integraban el pueblo del que se tratara, centrando así su análisis en la problemática político-jurídica vinculada de forma estrecha con las características de cada pueblo. Posteriormente, viajó a Venezuela, donde nuevamente vivió la dictadura, ahora con Guzmán Blanco, y pronto fue expulsado del país. 
De su paso por México, Guatemala y Venezuela salió Martí fortalecido en sus convicciones latinoamericanistas. Comprendió la naturaleza de los Gobiernos y la necesidad de realizar un cambio urgente en la esencia de sus mecanismos, a fin de lograr la participación del pueblo y de cada uno de sus ciudadanos de forma activa en la vida pública de cada nación. Influyó radicalmente además en sus concepciones ético-jurídicas, pues fue a partir de la realidad de Nuestra América que Martí pudo exponer con claridad sus teorías respecto al Gobierno y a la política, sustentadas en la actuación de un gobernante que se identificara con su país y respondiera a los intereses de su pueblo, que era, en fin, del que emanaba todo su poder, tarea esta que exigía a su vez el respeto de los valores éticos que constituían la base de la moralidad nacional.

En 1891, Martí publicó en la Revista Ilustrada de Nueva York y en El Partido Liberal de México, su emotivo ensayo "Nuestra América", en el que reiteraba sus ideas en defensa de la identidad y autoctonía latinoamericanas. Autoconciencia y unidad son los primeros consejos que Martí da a los pueblos latinoamericanos, pero para lograr su consecución era preciso erradicar algunos de los problemas que se habían mantenido en América desde la colonia, entre los que sobresalían el de la explotación de los indígenas, desposeídos de sus tierras y derechos, y el referido a aquellos que vivían en América pero se sentían europeos, renegando de lo propio, los desarraigados, a quienes Martí llamó "sietemesinos": "Estos nacidos en América, que se avergüenzan, porque llevan delantal indio, de la madre que los crió, y reniegan, bribones, de la madre enferma [...]" (Martí, 1975, p. 90).

En defensa abierta de los valores autóctonos de nuestras tierras, Martí destacaba que no era posible aplicar leyes europeas a nuestros países, puesto que estas no se acomodaban a su composición. De igual modo, dejó plasmados los requisitos que debía cumplir toda ley, y que fueron igualmente sintetizados por Santovenia (1942, p. 45):

En el espíritu, moderna, ajustándose así a las exigencias de la época dentro de la cual nace, y correspondiéndose con las condiciones económicas, políticas y sociales imperantes; en la definición, clara, cerrando el paso así a la interpretación perniciosa; en las reformas, sobria, contribuyendo de este modo al logro de un equilibrio de las fuerzas sociales; en el lenguaje, sencilla, estando al alcance de todas las inteligencias, y en el estilo, enérgica y airosa, lo que permite dar lustre al medio en que se produce y al mismo tiempo, facilita la adquisición de parte de la conciencia social. 
Nos alertó también Martí sobre que, para poder solucionar los problemas existentes en nuestros pueblos, los gobernantes debían basarse en los elementos propios de su país y no en los ajenos, pues el desconocimiento de lo que llamó "elementos naturales" de un país traía como consecuencia el establecimiento de las tiranías que habían asolado a los países americanos poco después de lograda la independencia, por lo que sentenciaba: "[...] La incapacidad no está en el país naciente, que pide formas que se le acomoden y grandeza útil, sino en los que quieren regir pueblos originales con leyes heredadas"m(Martí, 1975, pp. 16-17).

Se requería, por tanto, instaurar Estados constituidos mediante la unión de todas las personas, bajo leyes que aseguren la libertad natural -como primera condición-, así como las libertades civiles y políticas de cada uno de sus ciudadanos. Martí expresa y defiende el punto de vista de que la libertad cívica no es meramente un atributo posible de la vida social, sino una condición inalienable para poder vivir de acuerdo con la naturaleza del hombre, es un derecho natural humano.

Sobre la base de estas ideas es que Martí proyecta una república de unidad, ejercida por la comunidad soberana de individuos, donde la lucha, teniendo como base el ideal humanista oriente a los hombres hacia acciones éticas y políticas, o sea, prácticas revolucionarias radicales, en las que se unan amor y sabiduría, conciencia y ciencia, teoría y práctica.

Llegado a este punto, resulta válido destacar la influencia que, en la formación de las concepciones iusfilosóficas de José Martí en torno a la República, tuvo; por un lado, las ideas de Bolívar, y por otro, la influencia doctrinal que recibió de los republicanos españoles; todo lo cual se fundamentó además en los juicios críticos que emitió respecto a la realidad que se vivía en la República de los Estados Unidos, permitiéndole comprender la necesidad de instaurar en las naciones latinoamericanas una República Nueva, cuya novedad radicaría tanto en su forma, que debía ser original, como en su contenido, que daría fin al espíritu colonial y a los desequilibrios sociales, vertebrándose desde su propio tronco sobre la base del desarrollo nacional y el fortalecimiento de los valores éticos en cada uno de los ciudadanos.

El pensamiento republicano de Bolívar se sustentó fundamentalmente en la defensa de principios radicales, tales como la igualdad política y social, la fraternidad y la virtud pública, para a partir de ellos poder entonces asegurar la libertad de los ciudadanos, eliminar los conflictos étnicos y sociales entre ciudadanos libres y evitar que las costumbres pervertidas por años de dominación arbitraria española 
acabaran con la república. Además, para el Libertador, una de las primeras virtudes a consagrar en la república era la obediencia a la ley, exigiendo a la vez que la misma no fuera arbitraria, sino resultado de la voluntad ciudadana; voluntad esta que, sin embargo, necesitaba ser formada y educada.

Por su parte, existían tres corrientes en las que se dividía el republicanismo en España: un ala de izquierdas, radical, democrática, federalista e insurgente. Para ellos la revolución debe ser atea, negadora de la autoridad, popular, fraternal y radicalmente democrática, pues la república ha de estar regida por el pueblo, las clases productoras de la sociedad, los artistas, los artesanos, los obreros, esta es la tendencia más influyente del republicanismo y con más arraigo entre las clases populares españolas. En el centro, con Nicolás Salmerón a la cabeza, se encuentran aquellos republicanos que rechazan la vía insurgente y promueven la vía institucional para luchar por una mayoría parlamentaria que favorezca la transición de la monarquía a la república. La derecha republicana, por último, tiene un papel insignificante a mediados del XIX -son los monárquicos quienes ocupan en España el espacio político de derechas-.

Estas ideas recorrieron Europa y América e influyeron en el pensamiento de los cubanos cuando Martí era apenas un adolescente, constituyendo, a la vez, fuentes que fueron nutriendo su ideal republicano y con las que tuvo una relación directa cuando vivió en España en los años comprendidos entre 1871 y 1874.

Durante esta etapa ocurrió en ese país un hecho significativo para las concepciones republicanas del Apóstol. Se trata de lo acontecido el 11 de febrero de 1873, cuando se produjo la abdicación del rey Amadeo de Saboya y la proclamación de la república. Ante este acontecimiento Martí, con una idea bastante clara de lo que debía ser una república, publicó un texto bajo el título $L a$ república española ante la Revolución cubana en el que reclamó a los diputados republicanos españoles el otorgamiento a Cuba de la misma libertad por la que ellos habían luchado, sobresaliendo, asimismo, sus pronunciamientos en torno al derecho que toda nación tenía de proclamarse libre y soberana.

La argumentación central radicaba en el hecho de que, como bien él expresara: "Si España se torna republicana, ¿cómo, sin negarse a sí misma, no ha de reconocer a la república cubana, sustentada por las armas insurrectas?" (Martí, 1975, p. 89) "[...] icómo ha de haber republicano honrado que se atreva a negar para un pueblo derecho que el usó para sí? La república no puede usar el derecho de la fuerza para oprimir a la república" (p. 91).

42 Trascendencia del pensamiento iusfilosófico de José Martí en la concepción de República para los pueblos de Nuestra América
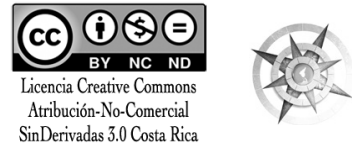

Yeneisi Bencomo-Fariñas 
El Maestro aprovechó así el cambio operado en España para presentar el problema cubano como una cuestión de derecho al novel régimen republicano, abogando por la libertad, así como por la instauración en Cuba de una república que enarbolara el respeto a la soberanía y a las consultas populares. En sus análisis, Martí no podía concebir que el pueblo español ostentara el legítimo derecho de proclamar la república, en uso de su soberanía, y que no lo tuviese Cuba, preguntándose y preguntando al pueblo español si se le podía jurídicamente negar a Cuba el ser libre y estructurarse sus instituciones públicas acorde con la decisión del país. Partió de la idea de que la soberanía residía en el pueblo, por lo que, si el pueblo cubano había decidido conquistar su libertad y erigirse en república, entonces la república española, si era verdadera, estaba obligada a acatar la decisión del pueblo cubano. Mostraba así los elementos del republicanismo fraternal que lo acompañaría toda la vida.

Así, con solo veinte años, José Martí le recordaba a la naciente república española el significado de la libertad republicana, que no era más que el derecho a vivir sin cadenas y sin amo alguno, bajo el amparo de leyes justas que reconocieran la igualdad plena de todos los ciudadanos, lo que indudablemente implicaba la eliminación de la esclavitud y de la opresión, así como el establecimiento de una relación fraternal entre los pueblos, concretando sus aspiraciones en una concepción republicana del patriotismo: "Patria es algo más que opresión, algo más que pedazos de terreno sin libertad y sin vida, algo más que derecho de posesión a la fuerza. Patria es comunidad de intereses, unidad de tradiciones, unidad de fines, fusión dulcísima y consoladora de amores y esperanzas" (Martí, 1975, p. 91). Aseguraba entonces Martí que el primer paso para llegar a la República consistía en independizarse de España, para después, al eliminar el espíritu colonial que sobreviviera, convertir a Cuba en una nación con todos sus derechos sobre la base de la defensa de la libertad, de la justicia y del fortalecimiento de los valores éticos. Estas ideas a las que arribara el Apóstol fueron además resultado de sus vivencias en el seno de la sociedad norteamericana en el período de 1881 a 1895 , donde pudo apreciar la erosión de los valores republicanos de ese país, y advertir el gran mal que padecía la República de los Estados Unidos: "[...] la acumulación ilimitada en unas cuantas manos de la riqueza de carácter público, priva a la mayoría trabajadora de las condiciones de salud, fortuna y sosiego indispensables para sobrellevar la vida. Ése es en los Estados Unidos el mal nacional"(Martí, 1975, p. 98).

El Apóstol avizoraba que la acumulación de riquezas volvía indiferentes a los hombres para las cuestiones públicas, arrasando al mismo tiempo con el 
valor republicano del cumplimiento del deber cívico, del patriotismo que buscaba no solo el progreso individual, sino también el progreso colectivo; de ahí que la mayor preocupación martiana fuera la pérdida de los valores republicanos. Fueron estas consideraciones las que le permitieron a Martí comprender la esencia y el cimiento mismo de toda república: los valores éticos, y a partir de ahí concibió su proyecto republicano, verdadera síntesis de la axiología ético-jurídica martiana.

Delineó pues una república cuya base sería la hondura de la eticidad que caracterizó a sus concepciones en todo momento, catalogándola, como nadie hasta entonces, República Moral, en defensa directa de la sociedad moral que propugnaba, cuyo centro no podía ser otro que el respeto a la dignidad humana, de modo que constituía un imperativo garantizar la igualdad social y el respeto al individuo. Para ello, se convierte la ética martiana en un instrumento dirigido a socavar las bases del régimen de explotación existente, pues consideraba Martí que un pueblo que cultivara los sentimientos, las virtudes y los valores humanos pondría en primer término la justicia y la moralidad ciudadanas, desdeñando así el afán del enriquecimiento y la desigualdad en todos los órdenes.
Centró su análisis en la defensa de la autoctonía de la república, y se dedicó a profundizar más en los valores éticos y axiológicos del espíritu de esta, que en sus formas, instituciones e instrumentos concretos de expresión.

El estudioso del pensamiento martiano, Dr. Julio Fernández Bulté, realizó en uno de sus artículos un interesante análisis acerca de cómo eran concebidas y asimiladas las categorías Forma de Estado y Forma de Gobierno durante los años en que se formaron y vertebraron las principales concepciones de Martí en relación con la organización del Estado, planteando al respecto que:

Ninguna de las corrientes jurisfilosóficas que pudo conocer Martí durante sus estudios y en los años posteriores, había logrado esclarecer, y ni siquiera esbozar, el elemento político y social del Estado: es decir, su base económica y sus componentes clasistas, mucho menos, por supuesto, revelar lo que hoy llamaríamos contenido y esencia, y que no es otra cosa que su definición: conjunto de instituciones, órganos, organismos y aparatos de los que se sirven una clase o alianza de clases para ejercer su dominio político de la sociedad. Cuando todos los filósofos anteriores habían quedado solo en el umbral estructural-funcional del Estado y del Gobierno, 
Martí descubre y devela su contenido social, su carácter de expresión de las estructuras sociales concretas; su formación a partir de las clases, los estratos sociales y los pueblos con su desarrollo determinado, sus tradiciones, su historia, su cultura. En Martí, como en todos los escritores de su épo$\mathrm{ca}$, no es sorprendente encontrar una sinonimia entre Estado y Gobierno, y aludir indistintamente a Formas de Gobierno cuando se está haciendo referencia a Formas de Estado. Pero lo esencial y lo que de forma más deslumbradora y notable salta a la vista es lo que ya se ha tratado de subrayar: Martí jamás esquematiza los mecanismos y formas de Estado y de Gobierno, aislando de ellos su esencia social, su contenido clasista. (Fernández, 2007, p.190)

Ello puede ser, por tanto, una explicación coherente del hecho mismo de que cuando se estudia la obra martiana sea frecuente que Martí se refiera a la república no como propiamente una forma de gobierno explicitada, sino como el tipo de sociedad necesaria para que esta se fundara después de lograda la independencia, en la que los valores éticos fueran su soporte y la República Moral su expresión.

Independientemente de que Martí no estudiara a la república como forma de gobierno propiamente dicha, no le quita méritos, al contrario, hay que valorar su posición al respecto en el contexto de la época en que vivió, donde existía una notable confusión en torno a las categorías Forma de Estado y Forma de Gobierno, y aún así, el Apóstol supo diseñar una república desde una concepción francamente renovadora y transformadora para su tiempo, en la que nos lega todo un cuerpo orgánico de valederos criterios en torno al orden económico, político y social que debía imperar en la sociedad; cómo debía ser concebida la política, el Gobierno, y sus formas, la proyección de Cuba en sus relaciones exteriores con los restantes países del mundo, avizorando importantes principios de derecho internacional público que son reconocidos por la comunidad jurídica internacional en nuestros días; sus criterios completamente revolucionarios en cuanto a la Constitución, ley principal de la república, entre otros aspectos de trascendental relevancia.

La actualidad de sus concepciones radica además en los postulados éticos que sirven de base a la sociedad, traducidos en una transparente armonía entre ética y derecho: "El problema de la independencia no era el cambio de formas sino el cambio de espíritu" (Martí, 1975, p. 19). 
$\mathrm{Su}$ pensamiento estuvo permeado además de la influencia del krausismo, siendo notorios los puntos de contacto entre su apreciación del Estado y el ideario jurisfilosófico del alemán: para este, el Estado y el derecho son resultado de una evolución dinámica, con creciente ampliación de contenido social. Es evidente la coincidencia: Martí advierte, con anticipada mirada dialéctica, el carácter evolutivo y dinámico del Estado, y no lo concibe sino como la expresión de un hondo contenido social, y defiende las formas originales y autóctonas que reflejan ese contenido, pero no abandona jamás la idea de la unidad americana. Es destacable también la noción krausista sobre el contenido jurídico del Estado y, a su vez, su comprensión de que este último no es simple ordenamiento normativo externo, positivo, sino un conjunto normativo de sentido moral. De ahí que Krause postule que el derecho va desde dentro, (la moral individual) hacia fuera, y una vez consagrado como tal el derecho actúa entonces desde fuera hacia dentro de la conciencia individual y social. No es difícil admitir que Martí hiciera suyas estas conclusiones de enorme carga ética.

Así, las bases esenciales de la república concebida por José Martí para Cuba y los demás pueblos de Nuestra América serían las siguientes:
El centro del proyecto republicano martiano lo encontramos en el presupuesto de la dignidad de todo ser humano, funcionando la dignidad como médula del suelo axiológico que permite construir el cuerpo de derechos humanos; de ahí que el respeto al individuo fuera su base constitutiva. La república martiana era "una república justa, con toda la vida adentro, sin exageración de un solo derecho, y sin olvido de ninguno" (Martí, 1975, p. 301).

Tenía que ser de sincera democracia, donde el hombre pudiera realizar a plenitud sus valores humanos, donde cada ciudadano tuviera oportunidad de ejercitar las capacidades legítimas del hombre de modo franco y cordial, dentro de un régimen de libertad y de justicia. La verdadera democracia, por tanto, era aquella que respondiera a los intereses y las necesidades materiales y espirituales de los ciudadanos, estableciendo como principio rector el respeto a las leyes y la plena igualdad ante estas, a la preservación de las libertades y derechos individuales y colectivos.

En la república martiana está siempre presente la defensa del principio de soberanía popular, como expresión del genuino poder político en manos del pueblo, depositario natural de la soberanía de la nación, y en función de esto determinó cómo era que debía funcionar el gobierno de la república: "El gobierno es un encargo popular: dalo el pueblo, a su satisfacción debe ejercerse, 
debe consultarse su voluntad, según sus aspiraciones, oír su voz necesitada, no volver nunca el poder recibido contra las confiadas manos que nos lo dieron, y que son únicas dueñas suyas" (Martí, 1975, p. 264). De tal modo, la república desde la visión martiana, tendría una sólida base popular.

La República que nos propone fundar el Apóstol tendría que ser inexorablemente nueva, incluso sin cometer los errores de las propias repúblicas latinoamericanas nacidas antes. Aludió en todo momento a la importancia de asumir en cada país lo mejor de su experiencia histórica, alimentándola con lo más positivo de la experiencia universal, siendo en él una constante la conservación y el fortalecimiento del nervio nacional: "Injértese en nuestras Repúblicas el mundo, pero el tronco ha de ser el de nuestras Repúblicas" (Martí, 1975, p. 265). Las raíces nacionales darían a cada pueblo la forma de gobierno justa que deberían asumir: "El gobierno ha de nacer del país. El espíritu del gobierno ha de ser el del país. La forma ha de avenirse a la constitución propia del país. El gobierno no es más que el equilibrio de los elementos naturales del país" (Martí, 1975, p. 21). Concluyó en tal sentido que los modelos de gobernabilidad irracional importados eran un atropello a lo autóctono de los países importadores, un ataque a su esencia natural, lo que tarde o temprano provocaría un aborto en los posibles resultados positivos de la gestión de gobierno. Para Martí la solución a la problemática no es ajustar la petición del naciente país a las formas de gobierno preestablecidas, sino ajustar estas a las necesidades históricas del nuevo Estado en lo que puedan ser oportunas y válidas.

Al expresar Martí que la incapacidad ha de recaer en los que imponen las formas de los gobierno distorsionadas y no en los pueblos a los que se les imponen, dejó expuesto tres aspectos esenciales, y que son analizados por el Doctor Tapia Sánchez (2005, P. 50), a saber:

Que la responsabilidad histórica, política y jurídica por la selección de una forma de gobierno sin sustento en los intereses y raíces propias corresponde exclusivamente a las capas gobernantes que así lo han decidido.

Que los modelos de gobierno europeos y norteamericano son incompatibles con la realidad latinoamericana y su importación acrítica será un fracaso.

Que cada nación que surge como nuevo Estado requiere de un nuevo Derecho tan original como ella misma y adaptado a su propia composición.

Sobre la manera en que debían proyectarse los gobernantes en el ejercicio de sus funciones, estableció entonces: "Los que han de conducir un día por prósperos caminos a la Patria, deben educarse vigorosamente, fortalecerse en la conciencia de sí propios, templarse al 
fuego vivo del Derecho, ley de paz de los pueblos libres, en la progresión sucesiva de las leyes de los pueblos de la tierra"(Martí, 1975, p. 90).

A partir de esta idea martiana, se puede afirmar que la teoría política de Martí partía de la idea del gobernante honesto, del estadista sagaz e indulgente, que no veía en la patria ni pedestal ni comodín, sino agonía y deber; por lo que, quien ejerciera el poder público, debía saber que lo tenía por merced y por encargo de su pueblo, como una honra que se le tributaba, y no como un derecho del que gozaba. Sobre la responsabilidad de los gobernantes, y la imperiosa necesidad de que estos, con su actuación, respondieran a los intereses del pueblo que los eligió, escribió Martí: "El jefe de un país es un empleado de la nación, a quien la nación elige por sus méritos para que sea en la jefatura mandatario y órgano suyo; así caen los gobernantes extraviados en los países liberales, cuando en su manera de regir no se ajustan a las necesidades verdaderas del pueblo que les encomendó que lo rigiese." (Martí, 1975, p. 123).

En este orden, José Martí reconoce y atribuye trascendental importancia al sufragio y al ejercicio del derecho al voto en la sociedad, como soporte también de la democracia

[...] su deber de hombres, el deber de que no puede desertar, so pena de deshonra y esclavitud, ningún ciudadano de República, el deber de votar [...] el hombre que no vota en una República es traidor a la República, traidor al hombre: donde no es ley aun el voto, porque no lo puede ser, es freno, es semilla; el voto, aun violado, es útil, porque el que lo viola, queda tachado de ladrón [...] en las Repúblicas es un deber ejercitar todos los derechos" (Martí, 1975, p. 247).

Comprendía entonces Martí, que el voto era un depósito delicadísimo, pues con él iban el interés, el porvenir, el honor y la vida del depositante. Lo quería eminentemente secreto, porque así se evitaba el predominio del soborno. A aquellos ciudadanos que se alejaban de las urnas, Martí les advirtió: "Si desdeñan hoy el ejercicio de su derecho de dueños, tendrán mañana que postrarse, aterrados, ante un tirano que los salve. [...] Es preciso, ante todo, ejercitar el derecho del voto, no ejercitarlo, descuidarlo, es perder un derecho, es construir la antesala del déspota." (Martí, 1975, p. 264).

Para el Maestro, la garantía de república a la que aspiraba estaría en el ordenamiento político, económico y social vigente, basado en el pleno respeto a las leyes que el país se diera, elaboradas por un Gobierno en el que todas las fuerzas sociales tuvieran una equitativa 
representación, como aparece esbozado en estas anotaciones suyas: "Ha de tenderse a una forma de gobierno en el que estén representadas todas las diversidades de opinión del país en la misma relación en que están sus votos." (Martí, 1975, p. 108).

Entendía asimismo que una ley tan básica como lo era la Constitución de un país, si no se atemperaba a la realidad social, podía caer en desuso, al menos en parte, con evidente daño a la causa pública. De tal modo, la Constitución de un país no podía elaborarse con abstracciones jurídicas, sino que debía ser reflejo de la naturaleza y las urgencias del país.

La política martiana, en relación con las restantes naciones del mundo, constituye otro parámetro que nos permite definir el tipo de república que aspiraba a fundar. Su concepción acerca de la unidad continental constituía la base de las relaciones jurídicas internacionales que se desarrollarían como parte de la política exterior de las naciones, siendo este un campo donde se revela la solidez de la formación de Martí como jurista. En este plano, abordó la necesidad de garantizar también, a partir del derecho internacional, la plena independencia y la autonomía de nuestros pueblos frente a cualquier intento de injerencia del extranjero. Según el Apóstol, los fundamentos estratégicos a partir de los cuales se habría de formular la política exterior de Cuba, una vez alcanzada la independencia, eran, como bien nos indica el autor Patricio González (1999, p. 148), "la defensa de la paz, la búsqueda de soluciones negociadas a los conflictos y la convivencia pacífica entre los Estados, como freno a las guerras de conquista, el respeto al Derecho Internacional, a la autodeterminación de los pueblos, la igualdad soberana y la no injerencia en los asuntos internos".

En la concepción martiana de la República Moral, las formas eran lo de menos. Su amplio espíritu se volcó íntegramente en la determinación de los valores y principios ético-jurídicos que habrían de guiar los pasos de la nueva república, advirtiendo que la lucha no terminaría con la conquista de la libertad política, sino con el triunfo pleno de las cualidades magníficas del hombre; centrando así su preocupación en los fines reales de la vida humana, en los objetivos que la sociedad debía proponerse, en el deber-ser de toda conducta racional, válida y justa.

Hoy, en América Latina, están en marcha procesos que retoman las ideas integracionistas de Martí, a favor de la independencia y la soberanía, puesto que las amenazas y los desafíos siguen siendo, en buena medida, aquellos que conoció y avizoró el prócer cubano.

Trascendencia del pensamiento iusfilosófico de José Martí en la concepción de República para los pueblos de Nuestra América 
Es que Martí articuló de manera correcta la realidad de la época en América Latina, permitiéndole explicar las consecuencias que se derivan de la desunión para nuestros pueblos, no solo en su lucha por la independencia social, sino que además consideró la integración como única alternativa posible en pos del logro de la segunda independencia, elementos universales y vigentes actualmente, si analizamos la situación socioeconómica que viven nuestros pueblos, donde se mantiene la estructura económica deformada en medio de un proceso de globalización neoliberal que aísla y margina a los países más pobres.

Por tanto, la integración de las naciones de Nuestra América, sin violentar la diversidad de culturas, economías, sistemas políticos y sociales, constituye una tarea de extrema urgencia si pretendemos lograr el tan anhelado equilibrio del mundo, que inexorablemente conllevaría a la formación de una cultura defensora de los valores más trascendentales que asegurarían la identidad y la supervivencia humanas, sobre la base, precisamente, de las ideas iusfilosóficas martianas que devienen armas ético-jurídicas en la consecución de tan nobles fines.

\section{Consideraciones finales}

En José Martí encontramos un vasto pensamiento iusfilosófico que trasciende a niveles de recurrencia y contemporaneidad tal, que lo convierten en un hombre de talla universal; cuyo pensamiento jurídico, articulado a partir de la ética, estuvo sellado por la Justicia como centro del Derecho, y rebasa las fronteras de su tierra para contextualizarse en la realidad de todas las naciones latinoamericanas.

Las concepciones ético-jurídicas del Apóstol no se derivan solo de una cultura libresca, sino de la constatación de realidades que aprecia, fundamentalmente, en su estancia en países de Nuestra América, donde escribió artículos cargados de reflexiones iusfilosóficas que le permitieron, a partir de la defensa de la identidad de nuestras naciones, comprender la necesidad de ajustar a estos conceptos las cuestiones referidas al Gobierno, los gobernantes, las instituciones del país, así como las leyes; consideraciones estas de Martí que evidencian la profundidad del pensamiento martiano en el ámbito de la filosofía del derecho, particularmente en lo relacionado con el iuspubliscismo.

La república concebida por el Apóstol aparece como una fusión de más de una categoría al uso; no fue concebida como una forma de gobierno propiamente dicha, sino que aludía a la nueva
50 Trascendencia del pensamiento iusfilosófico de José Martí en la concepción de República para los pueblos de Nuestra América

Yeneisi Bencomo-Fariñas

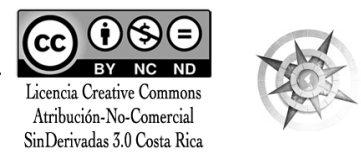


sociedad que aspiraba a construir en Cuba y restantes países latinoamericanos, y sustentada a su vez en los valores ético-jurídicos; cuyo centro no podía ser otro que el respeto a la dignidad plena del hombre, abogando en todo momento por el reconocimiento y consecuente protección de sus derechos, así como por la instauración en la sociedad de mecanismos verdaderamente democráticos que permitieran la participación activa de los ciudadanos en la vida pública de la nación.

La preservación de los valores autóctonos de Nuestra América y su afán por la integración de nuestros pueblos desde una unidad plena constituyen elementos rectores del pensamiento iusfilosófico martiano que demuestran cómo su reclamo de unidad y destino común para nuestras tierras mantiene plena su vigencia, y se materializa en el germinar de una América nueva.

\section{Referencias.}

Fernández, J. (2007). Aproximación al pensamiento iusfilosófico de José Martí, Revista de la Sociedad Cultural José Martí Honda, No. 21.

González, R. (1999). Cultura y política en Nuestra América, Anuario No. 22.

Martí, J. (1975). Obras Completas. La Habana: Editorial de Ciencias Sociales.

Tapia, C;. Tapia, I.(2005). Diccionario de citas del pensamiento jurídico martiano.La Habana: Editorial Capiro. 